\title{
Screening for prevention of cardiovascular complications in sports: the challenge going forward
}

\author{
Alexander Kiško ${ }^{1 *}$, Lubica Dernarová1, Anna Hudáková1, Nelli Kishko² \\ ${ }^{1}$ Faculty of Health Care, Prešov University in Prešov, Prešov, Slovak Republic \\ ${ }^{2}$ Medical Faculty, Uzhgorod National University, Uzhgorod, Ukraine
}

The three main features requested for the "ideal" pre-participation screening (PPS) in sports are cost-effectiveness, high diagnostic accuracy and feasibility in large populations. Controversy exists concerning increasing an efficacy of the PPS by using echocardiography (ECHO).

500 healthy athletes (aged: 16-32, median age $21 \pm 5,446$ males and 54 females [8:1], participating in sports like football, athletics, handball, cycling, basketball, gymnastics) were examined during the period from 2011-2013 in a pilot study focusing on the prevention of cardiovascular complications in sports. All of the athletes were screened according to European PPS protocol with history taking, physical examination and 12-lead ECG registration. Cardiovascular abnormalities were not detected in any case. After that conventional ECHO (M-mode and 2D modalities) the exam was performed in all of the athletes and a broad spectrum of cardiovascular abnormalities was found in 14 cases $(2.8 \%)$. In

Received: $17^{\text {th }}$ Apr 2014

*Address for correspondence: Faculty of Health Care, Prešov University in Prešov, 0801 Prešov, Partizanska 1, Slovak Republic.

Phone: +421907439977

E-mail: alexander.kisko@unipo.sk
$7(1.4 \%)$ athletes it was mitral valve prolapse (hemodynamically significant in 1 case), in $3(0.6 \%)$ - bicuspid aortic valve (significant aortic stenosis in 1 case) and in other 4 cases $(0.8 \%)$ it was myocarditis, myocardial bridging, noncompaction of the left ventricle and coronary artery fistula. In 4 athletes abnormalities that were found required a temporary or permanent sports activities cessation.

The postulate suggesting that inclusion of $\mathrm{ECHO}$ into the PPS protocol may not be cost-effective should be revised today. Currently conventional techniques like M-mode and 2D are inexpensive enough (about 6.00 Euros in Slovakia), technically simple to be performed in the field in large athletic population by pocket-size ultrasound systems, powerful enough for the efficient screening and thus hold the potential to enter a screening protocol.

Well-constructed, sufficiently powered, randomized and long-term controlled studies will allow an objective evaluation of ECHO contribution to the diagnostic evaluation of life-threatening cardiovascular abnormalities in athletes. Considering such evidence, a modified PPS protocol should probably be applied to the sports cardiology practice.

KEYWORDS: sudden cardiac death, athletes, prevention. CITATION: Cardiol Croat. 2014;9(5-6):254.

\section{Literature}

1. Price DE, McWilliams A, Asif IM, et al. Electrocardiography-inclusive screening strategies for detection of cardiovascular abnormalities in high school athletes. Heart Rhythm. 2014;11(3):442-9.

2. Angelini P, Vidovich MI, Lawless GE, Elayda MA, Lopez GA. Preventing sudden cardiac death in athletes: in search of evidence-based, cost-effective screening. Tex Heart Inst J. 2013;40(2):148-55

3. Kiško A, Dernarová L, Kmec J, et al. Manuál skríningového vyšetrenia mladych športovcov. Prešovská univerzita v Prešove, Fakulta zdravotníctva. Grafotlač, 2013 , 45 p. 